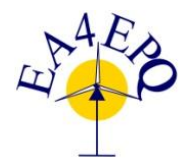

International Conference on Renewable Energies and Power Quality (ICREPQ'13)

Bilbao (Spain), 20 $0^{\text {th }}$ to $22^{\text {th }}$ March, 2013

Renewable Energy and Pourer Quality. Fournal (RE\&PQJ)

ISSN 2172-038 X, No.11, March 2013

\title{
A laboratory evaluation of the effectiveness of voltage unbalance factor of opposite temperature analysis of a three-phase induction motor
}

\author{
M. L. S. de Almeida ${ }^{1}$, J. A. A. Cormane ${ }^{1}$, A. L. Ferreira Filho ${ }^{1}$ \\ ${ }^{1}$ Department of Electrical Engineering \\ UnB, Brasília University \\ Campus Darcy Ribeiro - Asa Norte, Brasília (Brazil) Phone number:+ 556131071043 \\ e-mail: marialeonor.unb@gmail.com, jorgecormane@gmail.com, anesioleles@gmail.com
}

\begin{abstract}
This paper presents, based on experimental tests, an analysis of the effects of unbalance voltage on temperature rise of three-phase induction motor (TIM) with a view to evaluating effectiveness of the method of measurement employed, namely the method of symmetrical components. To do so, one motor is subjected to conditions of unbalance, strategically chosen, and their elevations of temperatures measured in three-phases are displayed. Among the many results obtained, it was found for voltage combinations where the voltage unbalance factor (VUF) has values very close to $0 \%$, the existence of temperature rises higher than those where the VUF is greater than $2 \%$. From investigations made, it is concluded that the use of VUF as single and sufficient index for the quantification of voltage unbalance is inappropriate.
\end{abstract}

\section{Key words}

Three-phase Induction Motor, Voltage Unbalance, Thermal Evaluation, Unbalance Factor.

\section{Introduction}

In many countries, number of researchers concerned with the quality of electric power gradually increases. These researchers expend efforts in order to improve standardization, quantification, identification of causes and effects, and mitigation of the impact of the phenomena related to power quality [1] - [2]. Among the problems related to this phenomenon, it is mentioned the voltage unbalance, responsible for compromising the performance of many equipment.

Currently, it is known that the presence of high levels of unbalance can cause excessive losses, overheating insulation degradation, and a reduction in the lifespan of motors and transformers. Equipment protection systems are also affected, leading to interruptions in production processes. Moreover, under such conditions, it is possible to detect the presence of harmonic currents not features, making it even harder to attempt to mitigate their effects.
Considering the effects caused by the unbalance, it emphasizes the need to consider carefully about adopting, proposition, methodologies definitions, evaluation indexes and the tolerable limits for this phenomenon [3] - [7]. These determinations are essential to contemplate and ensured the fundamental characteristics of power quality, namely: normal system operation, consumer's service within the satisfactory standards of quality, the acceptably preservation of life of elements and equipment of power system, energy efficiency, assignments of responsibilities, and economic and legal issues.

Based on the aspects mentioned herein, emerged the idea of development this work that presents the experimental results conducted to evaluate the effectiveness of the method of symmetrical components proposed for the quantification of voltage unbalance. The analyzes are grounded on changes in winding's temperature on each phase of the stator of a three-phase induction motor (TIM), supplied with unbalanced voltages. For this purpose, strategically chosen voltages combinations are applied on the TIM, with the following features:

1) Unbalances with voltage unbalance factor (VUF) close to zero, which are capable to cause temperature rises higher than those obtained for greater VUF, and

2) Unbalances with VUF practically equal, capable of generating different temperature rises at TIM.

Initially some aspects related to voltage unbalance are exhibited. Subsequently, the procedures and criteria used in the tests are presented, and also the results obtained.

\section{Voltage Unbalance and the VUF index}

Voltage unbalance is defined as any situation where voltage phasors have different magnitudes from each 
other, or lag angles are different from 120 electrical degrees between them or both situations [8].

In this work, the index of voltage unbalance, VUF (Voltage Unbalance Factor) is calculated by the symmetrical components method. Analytically, the symmetrical components are defined by the Fortescue matrix, shown in (1).

$$
\left[\begin{array}{l}
\overline{V_{A}} \\
\overline{V_{B}} \\
\overline{V_{C}}
\end{array}\right]=\left[\begin{array}{ccc}
1 & 1 & 1 \\
1 & a^{2} & a \\
1 & a & a^{2}
\end{array}\right]\left[\begin{array}{c}
\overline{V_{0}} \\
\overline{V_{1}} \\
\overline{V_{2}}
\end{array}\right]
$$

Where:

- $a$ is the rotational operator, whose magnitude is equal to one and its angle is $120^{\circ}$;

$-\overline{V_{A}}$ is the voltage in phase $\mathrm{A}$;

$-\overline{V_{B}}$ is the voltage in phase $\mathrm{B}$;

$-\overline{V_{C}}$ is the voltage in phase $\mathrm{C}$;

- $\overline{V_{0}}$ is the zero sequence component voltage;

$\overline{V_{1}}$ is the positive sequence voltage; and

$\overline{V_{2}}$ is the negative sequence voltage.

Based on this method, Brazilian Electricity Regulatory Agency (Agência Nacional de Energia Elétrica -ANEEL) sets the unbalance factor as (2), and also determines that the reference value in the distribution system buses, except for low voltage, must be equal or less than $2 \%$ [9].

$$
V U F=\frac{\overline{V_{2}}}{\overline{V_{1}}} * 100 \%
$$

Voltage unbalance has basically two origins: one related to the structure of electric grid and other related to the load [10].

The unbalance related to the structure is caused by asymmetry of the electrical system at the level of transmission and distribution. The lack of transmission lines transposition and the presence of unbalanced transformers and unbalanced capacitor banks are examples of causers of the disturbance mentioned previously. Due to the small variation of the electric system parameters this type of cause is practically constant.

The unbalance related to nature of load depends of the operating characteristics of customers. In this situation, the existent inequality between phase voltages occurs due to some factors, for example: presence of unbalanced threephase loads, bad single-phase load distribution and variation on demand cycles of each phase.
On the induction motor, voltage unbalance creates a torque with opposition to the movement of the rotor, which in addition to the natural operational torque, culminates in a pulsing torque on the axis of the machine. Thus, there is reduction on the speed and on the resulting torque [11] - [13], and increase of the losses and the temperature of the motor [14] - [18]. In this context, it can be observed the wear of the mechanical elements of the machine and, consequently, the lifetime reduction of the TIM.

\section{Methodology of Experimental Tests}

In this section, all the features and requirements of laboratory tests are described.

\section{A. Experimental assembly}

To evaluate the temperature, the tests used a three-phase squirrel-cage induction motor with the following specifications, provided by the manufacturer: $2[\mathrm{CV}]$, 220/380 [V], 4 poles, 60 [Hz], 1755 [RPM], insulation class F, rated full-load torque equal to $8.13[\mathrm{Nm}]$ and rated current equal to $6.15 \mathrm{~A}$. It was defined the TIM configuration according to the delta connection. It is emphasized that TIM has maintained its load constant at $100 \%$ in all assays.

Figure 1 shows schematically the experimental setup employed in the tests. In this figure, the equipment used and the connections to three-phase induction motor are shown.

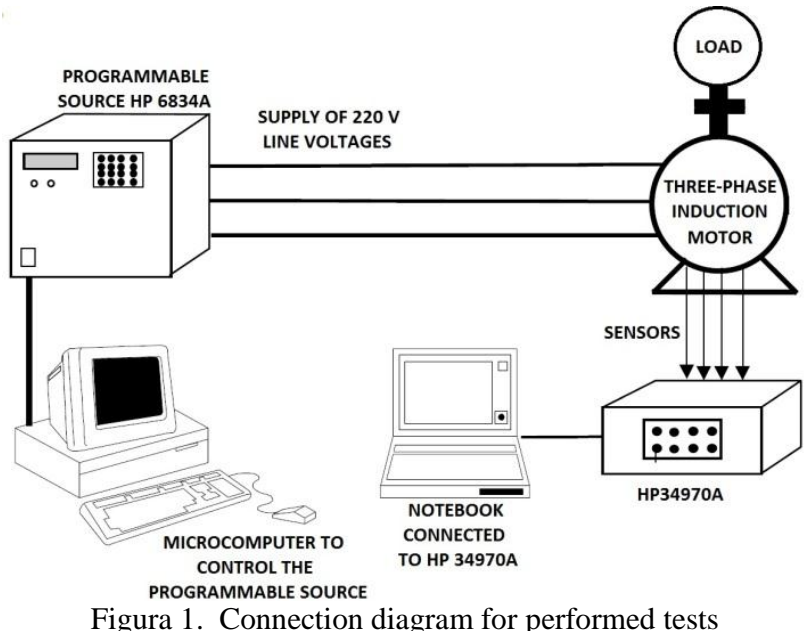

The units that make up the electrical circuit of the experimental setup are:

1) Programmable Source - supply the induction motor using a controllable voltage signal;

2) Microcomputer - to control, storing and processing the signals derived from the the programmable source;

3) Data acquisition system - for the measurement of temperature signals;

4) Three-phase induction motor; and

5) Direct current generator (DCG) - functioning as load. 
The analyzed machine is subjected to levels of unbalance, which are provided by a controlled source with power equal to $30 \mathrm{kVA}$.

\section{B. Requirements for the tests}

In regards literature, there are studies that highlight the importance of controlling environmental conditions for tests involving the analysis of temperature [18]. In this sense, some criteria were established in order to mitigate environmental differences between each of the tests. Following these precautions are presented.

1) The TIM was placed in an isolated environment to prevent the transit of people and air flow. The insulation occurred to minimize the influence of environmental agents on the temperature rise in the windings of TIM.

2) As it was the temperature analysis, characterized as a slowly transition parameter, became necessary to obtain measurements on steady state. For this reason, decay constant of the process was calculated to thereby determine the equivalent time of the on steady state [19]. The decay constant is approximately equal to 17 minutes. Having considered that the steady state is equal to 5 times the decay constant, was adopted as the test period the time interval equal to $1 \mathrm{~h} 30$.

3) The obtaining of the temperatures was performed by three temperature sensors of the type PT100, provided in each of the phases of the stator windings. The acquisition of the temperature occurred every ten seconds. This process was initiated along with TIM's energization, and finalized when it was shut down.

4) All essays began with the motor temperature in the range between $29.5^{\circ} \mathrm{C}$ and $30.5^{\circ} \mathrm{C}$. To make this possible, the temperature of the motor was controlled with the help of fans and an air conditioner (kept switched off during the tests). This procedure was rigorously practiced, in order to prevent a possible temperature gradient preexisting could influence the final results.

5) The essays were performed with three-phase induction motor operating under nominal load. This control of the TIM's load occurred by connection thereof to direct current generator.

\section{Essays for Determining the Effects of Unbalance on the Temperature}

At this stage of the study, voltage values (amplitudes and angles), strategically chosen, were used for supplying TIM.

In the first moment, it was decided to apply on the TIM a combination of three-phase balanced voltages. The results of this step are to provide reference for the analysis of temperature rise of the motor subjected to non-ideal conditions of operation. Thereafter, at the motor was applied some voltage phasors with unbalanced in amplitudes and angles, culminating in VUF between $0 \%$ and $2.75 \%$

\section{A. Ideal Supply Condition}

In this work, it was established temperature rise as the difference between the final and initial temperatures of each phase winding of the stator. Table 1 illustrates the results from the application of the rated voltage $(220 \mathrm{~V})$ for each phase of the TIM, and their respective temperature rises, when supply is balanced and without disturbances.

Table I. - Results from the application of balanced voltages

\begin{tabular}{|c|c|c|c|c|c|}
\hline $\mathrm{N}^{\circ}$ & $\begin{array}{c}\text { VUF } \\
(\%)\end{array}$ & Line Voltages & $\begin{array}{c}\Delta \mathrm{T} \\
\mathrm{A}\end{array}$ & $\begin{array}{c}\Delta \mathrm{T} \\
\mathrm{B}\end{array}$ & $\begin{array}{c}\Delta \mathrm{T} \\
\mathrm{C}\end{array}$ \\
\hline \multirow{2}{*}{1} & 0,12 & $\mathrm{Vab}=220,4 \angle 0^{\circ}$ & & & \\
& $\mathrm{Vbc}=220 \angle 240,43^{\circ}$ & 50,2 & 50,7 & 49,7 \\
\hline
\end{tabular}

From Table 1, it is observed that the temperature rise in each stage is approximately equal to $50^{\circ} \mathrm{C}$ - value adopted as the nominal temperature rise for the three phases. This is an elevation lower than that established by the insulation class of motor, namely the class $\mathrm{F}$, which allows a maximum temperature of about $155^{\circ} \mathrm{C}$ when the environment temperature equals $40^{\circ} \mathrm{C}$ [2].

Figure 2 illustrates the temperature rise obtained in the windings of phase A in the nominal supply condition.

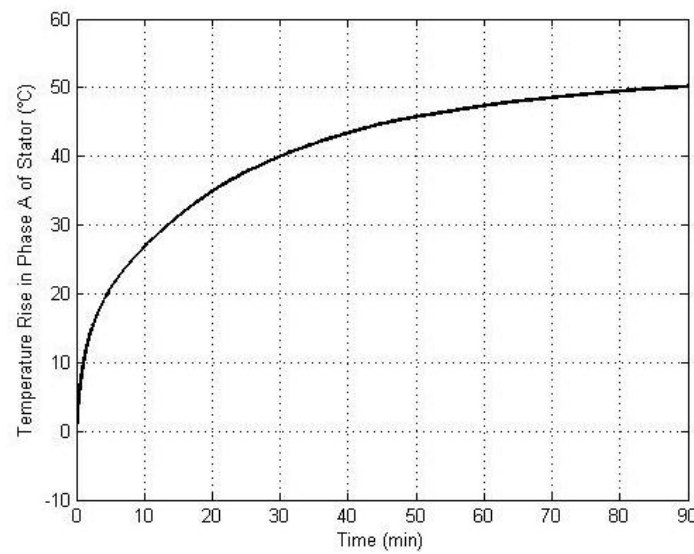

Fig. 2. Temperature rise curve in windings of phase A of the stator to the rated supply condition

From Figure 2, it is apparent that after a period of temperature rising, the machine tends to stabilize to the nominal supply condition at a level near $50^{\circ} \mathrm{C}$.

\section{B. Results of simulations with varying VUF}

The selection of the values of VUF for the execution of the experiments was such that the line voltages were between $201 \mathrm{~V}$ and $231 \mathrm{~V}$. These values are associated to the levels allowed by ANEEL that establishes this limit range for a system with nominal voltage equal to $220 \mathrm{~V}$ [9].

In Table II are illustrated the major results of the application of the motor unbalanced voltage where VUF varies between $0 \%$ and $2.75 \%$. 
Table III. - Results from the application of unbalanced voltages

\begin{tabular}{|c|c|c|c|c|c|}
\hline $\mathrm{N}^{\circ}$ & $\begin{array}{l}\text { VUF } \\
(\%)\end{array}$ & Line Voltages & $\begin{array}{c}\Delta \mathrm{T} \\
\mathrm{A}\end{array}$ & $\begin{array}{c}\Delta \mathrm{T} \\
\mathrm{B}\end{array}$ & $\begin{array}{c}\Delta \mathrm{T} \\
\mathrm{C}\end{array}$ \\
\hline 2 & 1,57 & $\begin{array}{c}\mathrm{Vab}=227,8 \angle 0^{\circ} \\
\mathrm{Vbc}=233,7 \angle 239,5^{\circ} \\
\mathrm{Vca}=229,1 \angle 118,47^{\circ}\end{array}$ & 58,1 & 54,3 & 52,9 \\
\hline 3 & 1,80 & $\begin{array}{c}\mathrm{Vab}=218,0 \angle 0^{\circ} \\
\mathrm{Vbc}=223,5 \angle 241,07^{\circ} \\
\mathrm{Vca}=224,4 \angle 119,32^{\circ}\end{array}$ & 51,9 & 47,4 & 50,0 \\
\hline 4 & 1,33 & $\begin{array}{c}\mathrm{Vab}=201,2 \angle 0^{\circ} \\
\mathrm{Vbc}=201,3 \angle 241,31^{\circ} \\
\mathrm{Vca}=205,2 \angle 120,61^{\circ}\end{array}$ & 50,6 & 49,3 & 52,0 \\
\hline 5 & 2,05 & $\begin{array}{c}\mathrm{Vab}=203,8 \angle 0^{\circ} \\
\mathrm{Vbc}=210,4 \angle 239,08^{\circ} \\
\mathrm{Vca}=204,3 \angle 117,93^{\circ}\end{array}$ & 49,9 & 46,1 & 44,3 \\
\hline 6 & 0,88 & $\begin{array}{c}\mathrm{Vab}=226,6 \angle 0^{\circ} \\
\mathrm{Vbc}=229,5 \angle 239,58^{\circ} \\
\mathrm{Vca}=226,6 \angle 119,14^{\circ}\end{array}$ & 54,9 & 53,5 & 51,5 \\
\hline 7 & 2,14 & $\begin{array}{c}\mathrm{Vab}=212,0 \angle 0^{\circ} \\
\mathrm{Vbc}=220,0 \angle 239,92^{\circ} \\
\mathrm{Vca}=215,8 \angle 118,12^{\circ}\end{array}$ & 53,6 & 48,3 & 48,4 \\
\hline 8 & 1,56 & $\begin{array}{c}\mathrm{Vab}=227,4 \angle 0^{\circ} \\
\mathrm{Vbc}=233,5 \angle 239,76^{\circ} \\
\mathrm{Vca}=229,6 \angle 1178,56^{\circ}\end{array}$ & 56,5 & 52,6 & 52,0 \\
\hline 9 & 2,07 & $\begin{array}{c}\mathrm{Vab}=201,4 \angle 0^{\circ} \\
\mathrm{Vbc}=203,7 \angle 241,96^{\circ} \\
\mathrm{Vca}=208,5 \angle 120,45^{\circ}\end{array}$ & 52,2 & 48,9 & 53,3 \\
\hline 10 & 0,38 & $\begin{array}{c}\mathrm{Vab}=214,3 \angle 0^{\circ} \\
\mathrm{Vbc}=215,0 \angle 240,37^{\circ} \\
\mathrm{Vca}=215,8 \angle 120^{\circ}\end{array}$ & 50,2 & 49,5 & 49,5 \\
\hline 11 & 1,20 & $\begin{array}{c}\mathrm{Vab}=221,2 \angle 0^{\circ} \\
\mathrm{Vbc}=216,9 \angle 239,59^{\circ} \\
\mathrm{Vca}=217,8 \angle 120,8^{\circ}\end{array}$ & 46,3 & 49,6 & 47,1 \\
\hline 12 & 0,21 & $\begin{array}{c}\mathrm{Vab}=201,3 \angle 0^{\circ} \\
\mathrm{Vbc}=200,9 \angle 239,84^{\circ} \\
\mathrm{Vca}=200,6 \angle 120,02^{\circ}\end{array}$ & 51,9 & 52,4 & 51,5 \\
\hline 13 & 2,16 & $\begin{array}{c}\mathrm{Vab}=219,5 \angle 0^{\circ} \\
\mathrm{Vbc}=224,5 \angle 241,73^{\circ} \\
\mathrm{Vca}=227,8 \angle 119,77^{\circ}\end{array}$ & 50,9 & 46,6 & 50,6 \\
\hline 14 & 2,75 & $\begin{array}{c}\mathrm{Vab}=201,2 \angle 0^{\circ} \\
\mathrm{Vbc}=201,6 \angle 242,77^{\circ} \\
\mathrm{Vca}=209,8 \angle 1121,3^{\circ}\end{array}$ & 49,7 & 47,0 & 53,0 \\
\hline 15 & 0,14 & $\begin{array}{c}\mathrm{Vab}=213,4 \angle 0^{\circ} \\
\mathrm{Vbc}=213,2 \angle 239,88^{\circ} \\
\mathrm{Vca}=212,9 \angle 120,01^{\circ}\end{array}$ & 47,4 & 47,6 & 46,7 \\
\hline 16 & 1,99 & $\begin{array}{c}\mathrm{Vab}=230,4 \angle 0^{\circ} \\
\mathrm{Vbc}=226,7 \angle 238,26^{\circ} \\
\mathrm{Vca}=226,6 \angle 119,98^{\circ}\end{array}$ & 52,4 & 56,6 & 50,0 \\
\hline 17 & 1,99 & $\begin{array}{c}\mathrm{Vab}=217,5 \angle 0^{\circ} \\
\mathrm{Vbc}=218,7 \angle 241,97^{\circ} \\
\mathrm{Vca}=224,5 \angle 120,73^{\circ}\end{array}$ & 49,7 & 47,5 & 52,0 \\
\hline 18 & 2,00 & $\begin{array}{c}\mathrm{Vab}=215,6 \angle 0^{\circ} \\
\mathrm{Vbc}=222,1 \angle 238,99^{\circ} \\
\mathrm{Vca}=215,5 \angle 117,98^{\circ}\end{array}$ & 54,4 & 51,0 & 48,4 \\
\hline 19 & 2,00 & $\begin{array}{c}\mathrm{Vab}=218,9 \angle 0^{\circ} \\
\mathrm{Vbc}=224,6 \angle 238,66^{\circ} \\
\mathrm{Vca}=217,3 \angle 118,04^{\circ}\end{array}$ & 53,3 & 50,4 & 47,2 \\
\hline 20 & 2,01 & $\begin{array}{c}\mathrm{Vab}=201,0 \angle 0^{\circ} \\
\mathrm{Vbc}=207,4 \angle 239,19^{\circ} \\
\mathrm{Vca}=201,7 \angle 118,01^{\circ}\end{array}$ & 53,4 & 49,6 & 47,8 \\
\hline 21 & 2,01 & $\begin{array}{c}\mathrm{Vab}=202,3 \angle 0^{\circ} \\
\mathrm{Vbc}=208,6 \angle 239,04^{\circ} \\
\mathrm{Vca}=202,6 \angle 117,99^{\circ}\end{array}$ & 51,5 & 48,0 & 46,2 \\
\hline
\end{tabular}

From Table II, it is observed:

1) The existence of voltage conditions where the VUF is near $0 \%$ culminating in temperature rises higher than those obtained for VUF above $2 \%$. For example, in case 12 , it is possible to identify temperature rises of the order of $52^{\circ} \mathrm{C}$ for $\mathrm{VUF}=0.21 \%$, when there for $\mathrm{VUF}=2.16 \%$ (case 13), elevations in three phasors below $51^{\circ} \mathrm{C}$. This same type of occurrence can also be identified by comparing the cases 12 e 5 .

2) By the same analysis, it's also possible to cite conditions of unbalance with lower values of VUF yielding temperature rises higher than those measured for conditions with greater VUF. Evaluating the case 6 where the VUF = $0.88 \%$, the elevations in three stages are higher than those found for the case 7 , wherein VUF $=$ $2.14 \%$. The pairs 2 and 3 , and 4 and 5 also exemplify this type of occurrence.

3) In cases where voltages are lower, higher voltage values are not always guarantee of higher temperature. For exemplification of this point, see the cases 11 and 12, for which have been, respectively, VUF equal to $1.20 \%$ and $0.21 \%$. It can be seen that in two of the three phases, the elevation of temperature are lower than those found for the conditions where the values of the voltages are greatest. This is also true for the cases 14 and 15.

4) Cases from 16 to 21 , presents conditions under which the VUF is approximately equal to $2 \%$. It is expected, therefore, that in these six tests the temperature rises are close together. However, it is possible to observe that unbalance supply conditions applied, resulted in different heating on phases, thus causing elevations above and below the nominal.

\section{Conclusion}

This work presents the main results of experimental tests performed with a TIM with a view to evaluate the effectiveness of VUF factor in quantifying the unbalance. For this purpose, the temperature rises in the windings of the stator phases of a motor subjected to various temperature conditions were monitored.

The results showed conditions where VUF is near to zero (which in theory there should be no unbalances) can cause elevations in temperature higher than those obtained for unbalance conditions with VUF greater than $2 \%$ (limit considered for some rules which deal with the subject).

Furthermore, some of the cases presented illustrate situations where smaller VUF values caused higher temperature rises than those obtained for VUF larger. It was also found that the application of combinations of voltages with equal VUF may culminate in temperature increases in the stator phases with differences between 
them of approximately $20.8 \%$ relative to the nominal elevation.

Thus, it was found that an increase in the amount of VUF is not always associated with a proportional increase in temperature. Therefore, it is concluded with the execution of this study, that use of VUF as single and sufficient index for the quantification of voltage unbalance is inadequate.

\section{References}

[1] Emanuel, A. et al.. "Induction motor thermal aging caused by voltage distortion and imbalance: loss of useful life and its estimated cost." Industry Applications, IEEE Transactions on, v. 38, n. 1, p. 12 \{20, jan/feb 2002. ISSN 0093-9994.

[2] O. C. N. Souto, "Modelagem e Análise do Desempenho Térmico de Motores de Indução Sob Condições Não Ideais de Alimentação", $\mathrm{PhD}$ Thesis, Faculty of Electrical Engineering, Uberlândia, Brazil (2001), pp. 323.

[3] Lee, C. Y. et al.. "Effects of Various Voltages on the Operation Performance of an Induction Motor under the Same Unbalance Factor Condition". In: Industrial and Commercial Power Systems Technical Conference (1997), pp. 51-59.

[4] A. L. Ferreira, "Análise do Comportamento do Fator de Desequilíbrio Frente a Variação da Amplitude e do Ângulo da Tensão", PhD Thesis, Faculty of Technology, University of Brasília, Brasília, Brazil (2008), pp. 163.

[5] Anwari, M. and Hiendro, A.. "New Unbalance Factor for Estimating Performance of a Three-Phase Induction Motor With Under- and Overvoltage Unbalance". In: IEEE Transactions on Energy Conversion (2010), vol. 25, no 3.

[6] Anwari, M. and Hiendro, A.. "New Unbalance Factor for Estimating Performance of a Three-Phase Induction Motor With Under- and Overvoltage Unbalance". In: IEEE Transactions on Energy Conversion (2010), vol. 25, no 3.

[8] Oliveira, J. P. J.. "Um estudo da influência do intervalo de agregação nos métodos de quantificação do desequilíbrio de tensão". Graduate work, Faculty of Technology, University of Brasília, Brazil (2012), pp. 4.

[9] ANEEL. Procedimentos de Distribuição de Energia Elétrica no Sistema Elétrico Nacional - PRODIST; Módulo 8 Qualidade da Energia Elétrica. Brasília, p. 30, 2012.

[10]Matos, J. M.. "Avaliação dos Efeitos do Desequilíbrio de Tensão Sobre os Motores de Indução Trifásicos". Graduate work, Faculty of Technology, University of Brasília, Brazil (2012), pp. 79.

[11] Kini, P. G. and Bansal, R. C.. "A Novel Approach Toward Interpretation and Application of Voltage Unbalance Factor". In: IEEE Transactions on Industrial Electronics (2007), vol. 54, no 4, pp. 2315-2322.

[12] Wang, Y. J.. "Analysis of Effects of Three-Phase Voltage Unbalance on Induction Motors with Emphasis on the Angle of the Complex Voltage Unbalance Factor". In: IEEE Power Engineering Review (2001), vol. 21, no. 9, pp. 270-275.

[13] Siddique, A. et al.. "Effect of Voltage Unbalance on Induction Motors". In: Conference Record of the 2004 IEEE International Symposium on Electrical Insulation (2004), pp.26-29, Indianápolis, EUA.

[14] Faiz, J. et al.. "Precise derating of three-phase induction motors with unbalanced voltages.” In: Industry Applications Conference, 2005. Fourtieth IAS Annual Meeting. Conference Record of the 2005, vol. 1, p $485-491$.

[15] Mendes, E. C. et al.. "Influence of the Positive Sequence Voltage on the temperature of Three-Phase Induction Motors". In: XIX International Conference on Eletrictal Machines - ICEM (2010), Rome.
[16] Quispe, E. C. et al.. "Experimental Study of the Effect of Positive Sequence Voltage on the Derating of Motors under Voltage Unbalance". InElectric Machines Drives Conference (IEMDC), 2011 IEEE International. [S.l.: s.n.], 2011. p. 908-912.

[17] Gnacinski, P.. "Effect of unbalanced voltage on windings temperature, operational life and load carrying capacity of induction machine". In: Energy Conversion and Management 49 (2008) 761-770.

[18] Gnacinski, P.. "Windinsgs Temperature and Loss of Life of an Induction Machine Under Voltage Unbalance Combined With Over - or Undervoltages". In: transactions on Energy Conversion (2008), vol. 23, no. 2, pp. 363-371.

[19] Ogatta, K.. "Engenharia de Controle Moderno", Terceira Edição, LTC Editora (1998), p. 114-115. 